\title{
Sigortacılık ve ekonomik büyüme ilişkisi: G-8 ülkeleri için bir uygulama
}

\section{Relationship between insurance and economic growth: An application for G-8 countries}

Gönderim Tarihi / Received: 15.07.2021

Hasan MEMIS ${ }^{1}$

Kabul Tarihi / Accepted: 30.09.2021

Hüseyin ÇELIK ${ }^{* * 2}$

Doi: https://doi.org/10.31795/baunsobed.971904

ÖZ: Sigortacılık, ülkelerin ekonomik kalkınma ve büyüme düzeyleri yükseldikçe önemi daha da artan bir sektördür. Ayrıca sigortacılık sektörü ekonomik kalkınma ve büyüme süreçlerine pozitif etki sağlamaktadır. Çeşitlenen ekonomik faaliyetlerle beraber sigortacılık sektörünün de hizmet alanı ve kapsamı genişlemektedir. Sigortacılık sektörünün gelişmesi ile ekonomideki riskler minimize edilmektedir. Böylece riskler bertaraf edilerek iktisadi faaliyetlerden daha verimli sonuçlar elde edilebilmektedir. Bu çalışmanın amacı sigortacılık sektörünün ekonomik büyüme açısından önemini ortaya koymaktır. Çalışma G-8 ülkeleri için gerçekleştirilmiş ve 1996-2019 dönemini kapsamaktadır. Ekonometrik analizlerde IPS birim kök testi, Pedroni eşbütünleşme ve FMOLS katsayı tahmincisinden yararlanılmıştır. Elde edilen sonuçlar göre sigortacilık sektörü ile ekonomik büyüme arasında uzun dönemde bir ilişki bulunmuştur. Sigortacılık sektörünün ekonomik büyümeyi pozitif etkilediği görülmüștür.

Anahtar Kelimeler: Sigortacılık, Eşbütünleşme, Ekonomik büyüme

ABSTRACT: Insurance is a sector that has become more important as increase the economic development and growth level of the countries increase. Furthermore, the insurance sector has a positive influence on economic growth and development. Along with the diversified and developing economic activities, the service area and scope of the insurance sector are also expanding. With the development of the insurance sector, the risks in the economy are minimized. Thus, risks can be eliminated, and more efficient results can be obtained from economic activities. The aim of the paper is to denote the importance of insurance sector in terms of economic growth. The study included G- 8 countries and covered the 1996-2019 period. For the econometric analysis, we used the IPS unit root test, Pedroni cointegration test, and FMOLS coefficience. The results displayed that there is a long-run relationship between insurance sector and economic growth. Additionally, the insurance sector has a positive effect on economic growth.

Keywords: Insurance, Cointegration, Economic growth

\footnotetext{
** Sorumlu Yazar / Corresponding Author

1 Doç. Dr., Balıkesir Üniversitesi, İktisadi ve İdari Bilimler Fakülte/İktisat Bölüm, hasmemis@hotmail.com https://orcid.org/0000-0003-3312-9225

${ }^{2}$ Dr., Kilis 7 Aralık Üniversitesi, huseyinclk17@gmail.com, https://orcid.org/0000-0002-2455-9381
} 


\section{EXTENDED ABSTRACT}

\section{Literature review}

The insurance sector is an important sector in terms of both creating savings and eliminating risks in terms of economy. When we look at the literature, there are different studies that examine the insurance sector with various indicators and methods. While some studies deal with insurance sector macroeconomic level and others deal with different indicators as gross insurance Premium, total insurance volume, insurance consumption and individual retirement insurance ect. Moreover, in this study we focus on study that research to effect of insurance on economic growth. When we look for literature, we can find various study on insurance and economic growth. For instance, Apergis \& Poufinas (2020) Kaya \& Beşer (2020), Kumar et. al. (2020), Pradhan et. al. (2015), Horng et. al. (2012), Adetunji et. al. (2018) Pradhan et. al. (2015), Horng et. al. (2012), Ege and Saraç (2011). As result of this study in literature donate that insurance sector positively effect on economic growth. In this study that realized for G-8 countries we expected to have a positive impact.

\section{Methodology}

The aim of this study is examined linkage between insurance sector and economic growth. For this purpose, we used panel data analysis techniques because we have 8 countries. However, panel data analysis has a few advantages. At first one, Although the multicollinearity problem is encountered in the applications made with time series data, it causes less multicollinearity problems between the explanatory variables due to the fact that the values taken by the variables change depending on two dimensions with the use of panel data and to allows the creation and testing of more complex behavioural models from just cross-section data or just time series data (Baltagi, 2005). Second, by combining crosssection and time series observations of panel data analysis, it has a larger number of observations and thus enables more reliable estimations and increasing the degree of freedom depending on the increase in the number of observations (Hsiao, 2003) Allowing econometric analysis to be made even when short time series and/or insufficient cross-sectional observations exist, enabling the establishment of a dynamic model since the panel data also has a time dimension (Matyas \& Sevestre, 1996). Our data set is that consist of insurance service export and import, and economic growth covered period from 1996 to 2019 and we realized empiric analysis for G-8 countries. We take naturel logarithm of variable. At first step, we had run unit root test which check-up our variable whether stationary or not. As unit root test we used IPS unit root test (Im et al. ,2003). At second step, we have used Pedroni (1999) cointegration test. At last step of methodology, we estimate long-run coefficients with Fully Modified Ordinary Least Squares (FMOLS) method.

\section{Finding and discussion}

The study was carried out with the help of panel data techniques. First, unit root test was applied to the series. As a result of the unit root test, all variables were found to be stationary at the first difference. Stationary level is important for next step. The next step will select as variable is I (0) or I (1). Based on this result that all series I (1), panel cointegration test was applied by Pedroni (1999) cointegration test. From the results of the cointegration test, it was seen that there was a long-term relationship between the variables. Co-integration long-term coefficient estimates were made with Fully Modified Ordinary Least Squares (FMOLS) method. The coefficient estimates showed that the insurance sector positively affected economic growth.

According to the results obtained, it is seen that insurance services have a positive effect on economic growth. The development of insurance services is important for economies in different aspects such as saving and eliminating risks. If some policy recommendations are to be made in the light of the findings, necessary legal arrangements should be made for the development of insurance services in the country and government incentives for this area should be provided. Insurance services should be diversified and extended to the smallest economic activities. By taking into account the demand flexibility of insurance premiums and keeping insurance premiums at a reasonable level, wider masses should be able to benefit from these services. 


\section{Result and recommendations}

According to the results obtained, it is seen that insurance services have a positive effect on economic growth. The development of insurance services is important for economies in different aspects such as saving and eliminating risks. If some policy recommendations are to be made in the light of the findings, necessary legal arrangements should be made for the development of insurance services in the country and government incentives for this area should be provided. Insurance services should be diversified and extended to the smallest economic activities. By taking into account the demand flexibility of insurance premiums and keeping insurance premiums at a reasonable level, wider masses should be able to benefit from these services. 


\section{Giriş}

İnsanoğlu, yaşamı boyunca sosyal, ekonomik, sağlık vs. çeşitli riskler altında hayatına devam etmektedir. Söz konusu risklerin etkilerinden korunmak için farklı yöntemler geliştirilmiştir. Finansal alandaki riskleri minimize etmek için bazen bireylerin bir araya gelerek oluşturdukları sandıklar, fonlar, vakıflar veya bireysel tasarruflara yönelim bunlara örnek gösterilebilir. Günümüzde toplumların sosyal ve ekonomik hayatlarındaki değişmelerle birlikte bireyleri ekonomik ve hayati yönden zarar görme veya zarara uğratma risklerine karşı korumada uygulanan yöntem, sigortacılık sistemidir (Sezal, 2017: 1156). Hayati olsun mali olsun çeşitli riskleri bertaraf etmek amacıyla ortaya çıkarak hızla ilerleme kaydeden sigortacılık sektörü, sahip olunan varlıkları çeşitli risklere karşı güvenceye almaktadır. Sigortacılık işlemleri sayesinde bireyler, varlıklarını güvence altına alarak bir nevi iç huzur satın aldıkları ifade edilebilir. Bu güven ve huzur duygusuna iktisadi açıdan bakıldığında, bu güvenlik duygusu herhangi bir olumsuzluğun ortaya çıkması durumunda sigortalının tazmin edileceği bilgisinden kaynaklanmaktadır (Karaman ve Aydoğmuş, 2020: 3915).

Türk Ticaret Kanunu'nun 1263. Maddesinde sigorta şu şekilde tanımlanmaktadır: "Sigorta bir akittir ki, bununla sigortacı bir prim karşıllı̆ında diğer bir kimsenin parayla ölçülebilir bir menfaatini halele uğratan bir tehlikenin (bir rizikonun) meydana gelmesi halinde tazminat vermeyi yahut bir veya birkaç kimsenin hayat müddetleri sebebiyle veya hayatlarında meydana gelen belli birtakım hadiseler dolayısıyla bir para ödemeyi vs. edalarda bulunmayı üzerine alır."

Ayrıca literatürde sigorta kavramını açıklamayan çeşitli tanımlar yapıldığı görülmektedir. $\mathrm{Bu}$ tanımlardan bazılarına aşağıda yer verilmiştir. Sigorta, riskleri minimize etmek ve oluşan risklerin de ortaya çıkan zararlarını belirlemek amacıyla meydana getirilmiş toplumsal bir kurum olarak ifade edilebilir. Sigorta, çok sayıda ve benzer nitelikteki birimlerin tehdidi altında bulunduğu riskin neden olacağı zararların birlikte karşılaması amacıyla bir araya gelmesi ile meydana gelen bir bütün olarak ifade edilebilir. Diğer bir tanıma göre sigorta, aynı veya benzer riskle karşı karşıya kalan bireylerin, bireysel olarak belirgin olmayan hasar olasılıklarını belirgin bir hale kavuşturarak ve söz konusu olasılığın ortaya çıkmasıyla doğacak zararları birlikte gidermek amacıyla, risk yönetim ve sorumluluğunu üstlenen birey, kurum veya kuruluş tarafindan organize edilmesidir (Asunakutlu, 2021).

Bir başka tanıma göre de sigorta, öncesinden bilinemeyen, ancak gerçekleşme olasılığı olan tehlikelere karşı kişileri ve varlıkları, belli prim mukabilinde güvenceye alan bir sistem olarak ifade edilebilir. Yani sigorta aracılığı ile risk kişi ya da kurumlar tarafından sigorta firmasına aktarılmaktadır. Sigorta hizmeti alan taraflar sigorta firmasina bir risk primi ödemektedirler. Dolayısıyla sigorta firmaları da sigorta hizmeti sunarak elde ettikleri bu fonların finansal piyasalara aktarılmasında aracı rolü görmektedirler (Yenisu, 2019: 207). Sigortacılık sektörü ekonomi için son derece önemlidir. Sigortacılık hizmetleri şirketler ve bireyler için riskleri bertaraf ederek üretimin artmasına katkı sağlar. Ayrıca sigorta şirketlerine ödenen primler ekonomi için tasarruf kaynağı oluşturmakta, söz konusu tasarruflarla sermaye piyasalarına fon temin edilmektedir. Dolayısıyla sigorta sektörü ekonomik büyümeye katkı sağlayan faktörlerden biridir.

Bu çalışmada sigortacılık hizmetleri gelişiminin ekonomik büyüme üzerindeki etkisi ortaya konulması amaçlanmaktadır. Çalışmada diğer çalışmalardan farklı olarak sigortacılık göstergesini temsilen sigortacılık alanındaki dış ticaret verileri kullanılmıştır. Böylelikle hem ekonomik büyüme hem de dış ticaret bağlamında sigortacılık sektörünün üzerine düşünülmesi sağlanacaktır. Çalışmanın planı giriş bölümünden sonra ikinci bölümde literatür taramasına, üçüncü bölümde veri seti, model ve yönteme, dördüncü bölümde ampirik bulgulara yer verip son bölüm ise sonuç ve öneriler şeklindedir.

\section{Literatür taraması}

Sigortacılık sektörü ekonomi açısından gerek tasarruf oluşturma gerekse de risklerin bertaraf edilmesi açısından önemli bir sektördür. Literatüre bakıldığında sigortacılık sektörünü çeşitli göstergelerle ve yöntemlerle alan farklı çalışmalar bulunmaktadır.

Apergis ve Poufinas (2020) tarafından yapılan çalışmada, 27 OECD ülkesi ele alınmıştır. Bu ülkelerle ile ilgili 2006-2016 dönemi için yaşam ve yaşam dışı toplam brüt sigorta primleri, buna ek olarak, kişi 
başına reel GSYH verileri, özel yatırımlar, kamu harcamalarının GSYH'ye oranı, ticarete açıklık, orta öğretim, mali gelişme ve doğrudan yabancı yatırım girişlerini dikkate alınmıştır. Elde edilen bulgular, sigorta sektörünün büyümesinin ekonomik büyümeye katkı sağlayacağı şeklindedir.

Kaya ve Beşer (2020) tarafından yapılan çalışmada 25 Avrupa Birliği ülkesinde sigorta prim hacminin bu ülkelerin ekonomik büyümesini nasıl ve ne yönde etkilediği araştırılmaktadır. Makalede Johansen Eşbütünleşme, Kao eşbütünleşme, panel FMOLS, panel nedensellik yöntemlerinden yararlanılmıştır. Ekonomik büyüme ve sigorta prim hacmi arasında eşbütünleşme ilişkisi olduğu görülmüsstür. Panel FMOLS testinin sağladığı sonuçlara göre ise sigorta prim hacimlerindeki \%1 düzeyindeki artış, ekonomik büyümeyi \%0.113 arttırmaktadır. Panel nedensellik sonuçlarına göre ise sigorta hacimlerinden ekonomik büyümeye doğru olmak üzere tek yönlü nedensellik bulunmuştur.

Gümüş (2020) tarafından yapılan çalışmada, finansal gelişmişlik ve insani gelişmişlik endeksleri ile sigorta primleri arasındaki ilişki panel nedensellik ve eşbütünleşme metodu ile incelenmektedir. Çalışma OECD ülkelerinin 2009-2016 yıllarına ait verileri ile gerçekleştirilmiştir. Nedensellik testleri sonucunda insani gelişmişlik ile finansal geliş̧mişlikten sigorta primlerine doğru tek yönlü nedensellik elde edilmiştir.

Kumar vd. (2020) tarafindan yapılan çalışma, 1990-2016 döneminde Hindistan'da ekonomik büyüme ve sigorta tüketimi arasındaki ilişkiyi araştırmayı amaçlamaktadır. Makalede, Johansen eşbütünleşme tekniği ile ekonomik büyüme ve sigorta tüketimi arasındaki ilişkiyi incelemek amacıyla yıllık sigorta penetrasyonu, sigorta yoğunluğu ve kişi başına GSYH kullanılmıştır. Uzun vadede sigorta penetrasyonundan ekonomik büyümeye kadar uzanan tek yönlü bir nedensellik ortaya çıkmaktadır. Benzer şekilde, sigorta yoğunluğu da uzun vadeli ekonomik büyümeye neden olur. Hindistan'da sigorta penetrasyonu kısa vadeli ekonomik büyümeye yol açar. Ancak ekonomik büyüme, uzun vadede olduğu gibi kısa vadede de sigorta yaygınlığına veya yoğunluğuna neden olmamaktadır.

Yenisu (2019) tarafından yapılan çalışmada Türkiye için sigortacılık sektörü ile ekonomik büyüme arasındaki ilişki incelenmiştir. Analizlerde 2010Q1-2018Q4 dönemine ait veriler kullanılmıştır. Sigortacılık sektörü ile ekonomik büyüme arasındaki ilişkinin hem kısa hem de uzun dönemde anlamlı olduğu sonucuna ulaşılmıştır.

İslamoğlu vd. (2020) tarafından yapılan çalışmada, G7 ülkelerinde ve Türkiye'deki bireysel emeklilik sistemi karş1laştırmalı olarak incelenmiştir. Sonraki aşamada bireysel emeklilik sisteminin SWOT analizi gerçekleştirilmiştir. Çalışmada elde edilen veriler, katılımcıların sisteme dahil oldukları yılı, yaşlarına göre dağılımlarını ve fonlar tablolar yardımıyla gösterilmiştir. Çalışmanın sonucunda Türkiye'nin diğer ülkelere göre bireysel emeklilik sistemini daha iyi bir düzeye taşıdığı görülmüştür.

Lee vd. (2018) tarafından yapılan çalışmada bir ülkenin kişi başına düşen GSYH düzeyinin sigortacılık faaliyetleri ile ekonomik büyüme arasındaki ilişkiye etkisinin incelemesi amaçlanmıştır. Çalışmada 1967-2014 dönemi dikkate alınarak 123 ülkenin verileri değerlendirilmiştir. Bir ülkenin kişi başına düşen GSYH düzeyinin ekonomik büyümeye etkisini değerlendirmek için hem statik panel modeli hem de dinamik panel modeli kullanılmıştır. Bulgular, sigortacılık sektörünün gelişimi ile ekonomik büyüme arasında istatistiksel olarak anlamlı bir nedensellik ilişkisi olduğunu göstermektedir.

Adetunji vd. (2018) tarafından yapılan çalışma, Nijerya'daki sigorta faaliyeti ile ekonomik büyüme arasında ilişkiyi belirlemeyi amaçlamaktadır. 1996-2015 dönemi Nijerya zaman serisi verilerine Sıradan En Küçük Kareler modelinin uygulanması, sigorta sektörünün Nijerya'nın ekonomik büyümesine olumlu ve anlamlı katkı yaptığını ortaya koymaktadır.

Akın (2018) tarafından yapılan çalışmada MINT ülkelerinde çeşitli makroekonomik göstergelerin sigortacılık sektörü üzerindeki etkisi ele alınmıştır. Çalışmada MINT ülkelerinde sigortacılık sektörünün durumu farklı sigorta göstergelerinden yararlanılarak karşıllaştırmalı olarak ele alınmıştır. Makroekonomik performansa göre MINT ülkelerinde sigortacılık sektörünün yeteri düzeyde gelişim göstermediği görülmüştür. 
Akpınar ve Yıldız (2018) tarafından yapılan çalışmada, 2008 Finansal Krizinin dünya sigortacılık sektörü üzerindeki etkileri ele alınmıştır. Ayrıca çalışmanın diğer bölümünde Türkiye sigortacılık sektörüne ait değişkenlerden yararlanılarak 2007-2016 dönemi finansal performansı değerlendirilmiştir. Sigortacılık sektörünün finansal performans ölçüm değerlendirmesi TOPSIS ile yapılmıştır. Elde edilen analiz sonuçlarına göre ilerleyen yıllarda sigortacılık sektörünün önemli ilerlemeler kaydettiği görülmüştür. 2008 Finansal Krizinin sigortacılık üzerinde herhangi bir negatif etkisi olmadığ1 belirtilmiştir.

Demirci ve Zeren (2017) tarafından yapılan çalışmada, 1983-2011 dönemleri dikkate alınarak 13 OECD ülkesi için kişi başına düşen gelir ve kişi başı sigorta primleri arasındaki ilişki panel nedensellik yöntemi ile irdelenmiştir. Panel nedensellik testi sonuçlarına göre sigorta primlerinden GSYH'ye doğru tek yönlü bir nedensellik elde edilmiştir. Elde edilen nedensellik ilişkisine ait ülke bazlı sonuçlara göre İspanya, Fransa, İtalya ve İzlanda için elde edilirken diğer ülkeler için nedensellik ilişkisi elde edilememiştir.

Pradhan vd. (2017) tarafindan yapılan çalışmada, 1980 ve 2014 yılları arasında G-20 ülkelerinin ekonomik büyümesine ilişkin bankacılık sektörü ile sigorta sektörü arasındaki karşılıklı bağlantıları incelenmektedir. Vektör oto-regresyon modeli ve Granger nedensellik testinin kullanıldığı çalışmada, uzun vadede, bankacılık sektörü ve sigortacılık sektöründeki gelişmelerin G-20 ülkelerinin ekonomik büyümesini önemli ölçüde etkilediği tespit edilmiştir. Pradhan vd. (2016) tarafından yapılan çalışmada, 1988-2012 dönemi için Güney Doğu Asya Ülkeleri Birliği (ASEAN) Bölgesel Forumu (ARF) ülkelerinin panel verileri kullanılarak, sigorta piyasası penetrasyonu, geniş para, hisse senedi piyasası kapitalizasyonu ve ekonomik büyüme arasında Granger nedensellik ilişkilerinin olup olmadığı araştırılmaktadır. Sonuç olarak, tüm değişkenlerin eşbütünleşme ilişkisi olduğu ve ekonomik büyüme ile sigorta piyasası penetrasyonu arasında kısa vadeli çift yönlü nedensellik dâhil olmak üzere bir nedensellik ilişkisi bulunduğu tespit edilmiştir. Pradhan vd. (2015) tarafından yapılan başka bir çalışmada, sigorta piyasasının gelişimi, finansal gelişme ve ekonomik büyüme arasındaki nedensellik ilişkiler incelenmiş̧ir. Makalede 1988-2012 dönemi dikkate alınmış, 34 OECD ülkesinin ilgili panel verileri kullanılarak sigorta piyasası gelişiminin, mali gelişmenin ve ekonomik büyümenin eşbütünleşmiş olduğu ortaya konulmuşstur.

Lee vd. (2013) tarafından yapılan çalışmada, Dünya Bankası'nın yüksek, orta ve düşük gelirli ülke sınıflandırma kriterleri dikkate alınarak, 41 ülkenin 1979-2007 dönemini kapsayan panel setleri ele alınarak bu ülkelerin hayat sigortası primleri ve reel GSYH'si arasındaki ilişki incelenmiştir. Makalede uzun dönemde ekonomik faaliyet seviyesi ile hayat sigortası piyasaları arasında pozitif bir çift nedensellik ilişki olduğunu gösterilmiştir. Bu anlamda, yüksek düzeyde bir ekonomik büyümenin, yüksek bir sigorta prim düzeyine yol açacağı ve bunun tersinin de geçerli olacağı vurgulanmıştır.

Ege ve Saraç (2011) tarafindan yapılan çalışmada, 1999-2008 dönemi için gelişmiş 29 ülkeye ait veriler kullanılarak sigortacılık sektörünün ekonomik büyüme üzerindeki etkisi test edilmiştir. Analiz sonuçlarına göre, sigortacılık sektörü ve ekonomik büyüme arasında istatistiksel olarak anlamlı ve pozitif bir ilişkinin var olduğu görülmüştür.

Horng vd. (2012) tarafından yapılan çalışmada, 1961 ile 2006 yılları arasında Tayvan'daki sigorta talebi, finansal gelişme ve ekonomik büyüme arasındaki dinamik ilişkiyi incelenmektedir. Makalede üç değişkenli Vektör Otoregresif (VAR) modeli kullanılmış, sigorta talebi, finansal gelişme ve ekonomik büyüme arasında bir denge ilişkisi olduğu tespit edilmiştir. Kısa vadede, ekonomik büyüme Granger sigorta talebine neden olmakta ve finansal gelişme Granger ekonomik büyümeye neden olmaktadır. Başka bir deyişle, finansal gelişme, gerçek GSYIH büyümesini teşvik etmekte ve reel GSYH'deki bir değişiklik, Tayvan'daki reel sigorta talebinde sapmaya yol açmaktadır.

Literatür incelendiğinde sigortacıllk ve ekonomik büyüme ilişkisinin zaman serileri ve panel veri teknikleri ile çeşitli çalışmaların yapıldığı görülmektedir. Ayrıca sigortacılık sektörü farklı çalışmalarda çeşitli göstergelerle ifade edilmiştir. Elde edilen sonuçlardan genel olarak sigortacıllk ve ekonomik 
büyüme arasında uzun dönemli bir ilişki olduğu görülmektedir. Bu çalışmadan literatüre paralel sonuçlar elde edilmesi beklenmektedir.

\section{Yöntem}

\section{Veri seti ve model}

Bu çalışmada sigortacılık hizmetleri gelişiminin ekonomik büyüme üzerindeki etkisi araştırılmaktadır. $\mathrm{Bu}$ doğrultuda ekonometrik modelde sigortacilık hizmetleri gelişimini temsilen sigortacilık ve finans hizmetleri ihracatı (EXP) ve sigortacılık ve finansal hizmetleri ithalatı (IMP) alınmıştır.

Anılan ihracat ve ithalat, sigortacılık hizmetleri ihracat ve ithalatının toplam mal ve hizmet ihracat1 içindeki oranını temsil etmektedir. Ekonomik büyüme değişkeni olarak GSYH (Constant LCU) alınmıştır. GSYH'nin doğal logaritması alınarak modele dahil edilmiştir. Diğer değişkenler oran olarak temsil edildiğinden logaritma alınmadan modele dahil edilmiştir. Veriler Dünya Bankasından elde edilmiş ve 1996-2019 dönemini kapsamaktadır. Uygulamalar G-8 ülkeleri için gerçekleştirilmiştir.

Değişkenler arasındaki ilişki fonksiyonel olarak aşağıdaki şekilde ifade edilebilir:

$$
G D P=f(E X P, I M P)
$$

Ekonometrik yöntemler aşağıda Denklem 1'de ifade edilen matematiksel model ile araştırılmıştır.

$$
G D P_{i t}=\beta_{0}+\beta_{1} E X P_{i t}+\beta_{2} I M P_{i t}+\varepsilon_{i t}
$$

Burada, $i$, yatay kesitleri; $t$, zaman boyutunu; GDP, ekonomik büyümeyi; EXP, sigortacıllk hizmetleri ihracatını; IMP, sigortacılık hizmetleri ithalatını temsil etmektedir. $\beta$, uzun dönem katsayılarını ve $\varepsilon$, hata terimini göstermektedir.

Çalışmanın yönteminde panel veri analizlerden faydalanılmıştır. IPS birim kök testi, Pedroni eşbütünleşme testi ve FMOLS katsayı tahmincisi kullanılmıştır.

\section{IPS birim kök testi}

Yatay kesitler ve zaman serilerinden oluşan panellerde de değişkenlerin durağan düzeyinin ortaya konulması, eşbütünleşme derecelerinin belirlenmesi açısından birim kök testlerinden faydalanılmaktadır. Eşbütünleşme ilişkisinin araştırılmasında hangi eşbütünleşme testlerinin kullanılabileceğine karar vermede önemlidir. Tüm değişkenlerin I (1) olması durumunda veya bazı değişkenlerin I(0) bazılarının ise I(1) olması durumunda kullanılacak eşbütünleşme testleri farklıdır. Ekonometrik uygulama temelinde gerçekleştirilen çalışmalarda doğru eşbütünleşme testleri ile devam edilebilmesi için değişkenlerin eşbütünleşme dereceleri ve dolayısıyla bunun için de birim kök testleri önem arz etmektedir.

Bu çalışmada birim kök testi olarak Im, Peseran \& Shin (2003) (IPS) testi kullanılmıştır. Bu test paneldeki birimlere ait ortalama istatistik değerlerine dayalı işleyen testlere bir alternatif olarak geliştirilmiştir. Özellikle bu test ile, her bir grup için hesaplanan Dickey-Fuller istatistiklerinin ortalamalarına dayalı bir test önerilmiştir. IPS birim kök testi, seri korelasyonu, heterojenlik ve gruplar aras1 hata varyanslarına izin vermektedir (Im vd. 2003: 54). Bu varsayımlar altında hesaplanan IPS istatistikleri aşağıdaki şekilde hesaplanmaktadır (Im vd. 2003: 63):

$$
\Delta y_{i t}=\alpha_{i}+\beta_{i} y_{i, t-1}+\sum_{j=1}^{p_{i}} \rho_{i j} \Delta y_{i, t-j}+\varepsilon_{i t} \quad i=1, \ldots N, t=1, \ldots, T,
$$

IPS panel birim kök testine ait hipotezler ise;

$$
\begin{aligned}
& H_{0}: \beta_{i}=0, \quad \text { bütün i'leriçin, } \\
& H_{0}: \beta_{i}<0, \quad i=1,2,3, \ldots N_{1}, \quad \beta_{i}=0, \quad i=N_{1}+1, N_{1}+2, \ldots . N
\end{aligned}
$$


Burada, testin "panel için birim kök yoktur" temel hipotezine karşı "bazı i'ler için birim kök vardır" alternatif hipotezi sınanmaktadır.

\section{Pedroni eşbütünleşme testi}

Modeli oluşturan tüm serilerin I (1) mertebesinde eşbütünleşik olduğu sonucuna ulaşıldıktan sonra, eşbütünleşme ilişkisi Pedroni (1999) eşbütünleşme testi ile araştırılmıştır. Daha önce Pedroni (1995, 1997) testlerinin aksine birimlerin kendilerine özgü özelliklerini yani heterojenliği dikkate almaktadır. $\mathrm{Bu}$ testin diğer önemli bir özelliği, sadece paneldeki birimler arasında dinamik ve sabit etkilere izin vermemekte, aynı zamanda eşbütünleşik vektörün alternatif hipotezi altında birimler arasında farklılık göstermesine de izin vermektedir. Aksi halde eşbütünleşen vektörün homojenliğinin basitçe empoze edilmesi, değişkenlerin gerçekte eşbütünleşme ilişkisine sahip olmalarına rağmen, eşbütünleşme yoktur şeklindeki temel hipotezin kabul edilmesine neden olabilmektedir (Pedroni, 1999: 656-657).

Pedroni (1999) eşbütünleşme testi aşağıdaki şekilde elde edilmektedir (Pedroni, 1999: 657):

$$
\begin{gathered}
y_{i, t}=\alpha_{i}+\delta_{i} t+\beta_{1 i} x_{1 i, t}+\beta_{2 i} x_{2 i, t}+\cdots+\beta_{M i} x_{M i, t}+e_{i, t} \\
t=1, \ldots, T ; i=1, \ldots, N ; m=1, \ldots, M
\end{gathered}
$$

Burada, $T$, zaman boyutunu; $N$, paneldeki yatay kesitlerin sayısını; $M$, regresyon değişkenlerinin sayısını ifade etmektedir. $\alpha_{i}$, paneli oluşturan yatay kesitler arasında değişime izin veren yatay kesite özel kesişim noktası veya sabit etkiler parametresidir. Burada $\beta_{1 i}, \beta_{2 i}, . . \beta_{m i}$ paneli oluşturan yatay kesitler arası farklılık göstermesine izin veren eğim katsayılarıdır.

\section{Eşbütünleşme uzun dönem katsayi tahmincisi}

Uzun dönem eşbütünleşme ilişkisi elde edilen modelin uzun dönem eşbütünleşme katsayıları FMOLS tahmincisi ile gerçekleştirilmiştir. FMOLS katsayı tahmini hesaplanma prosedürü aşağıda verilmiştir:

$$
y_{t}=X_{t}^{\prime} \beta+D_{t}^{\prime} y_{1}+u_{1 t}
$$

Eşitlikteki $y_{t}$, I (1) bağımsız değiş̧keni ve $X_{t}^{\prime}$ ise $X_{t}=\tau_{21}^{\prime}+\tau_{22}^{\prime}+D_{2 t}+e_{2 t}$ ile $\Delta e_{2 t}=u_{2 t}$ ile ortaya konulan stokastik süreçlerdeki açıklayıcı değişkenleri göstermektedir. Ayrıca $D=\left(D_{1 t}^{\prime}, D_{2 t}^{\prime}\right)$ determistik trendine ait değişkenlerdir. $u_{1 t}$ ise sıfır ortalama ve kovaryanslı $(\Omega)$ hata terimini temsil etmektedir.

$$
\theta_{F M O L S}=\left[\begin{array}{c}
\beta \\
y_{1}
\end{array}\right]=\left[\sum_{T=1}^{T} Z_{1} Z_{t}^{\prime}\right]^{-1}\left[\sum_{T=1}^{T} Z_{t} y_{t}^{+}-T\left[\begin{array}{c}
\lambda_{12} \\
0
\end{array}\right]\right]
$$

$Z_{t}=\left(X_{t}^{\prime}, D_{t}^{\prime}\right)^{\prime}$ ve $y_{t}^{+}=y_{t}-\widehat{\omega}_{12} \widehat{\Omega}_{22}^{-1} \hat{u}_{2}$ dönüştürülmüş verileri sağlamaktadır. $\hat{\lambda}_{12}^{+}=\widehat{\omega}_{12} \widehat{\Omega}_{22}^{-1} \hat{u}_{2}, u_{t}=$ $\left(\hat{u}_{1 t}^{-1}, \hat{u}_{2 t}^{-1}\right)^{\prime}$ eşitliği ile tahmin edilmiş olan uzun dönem kovaryans-varyans matrisleri ile ilgili unsurlarla tahmin edilen sapma düzeltme terimidir (Işık vd. 2017, 89).

\section{Ampirik bulgular \\ Panel birim kök test sonuçlari}

Modele dâhil edilen değişkenlerin durağanlık mertebeleri IPS birim kök testi ile incelenmiştir. Birim kök testine ilişkin sonuçlar Tablo 1'de ifade edilmiştir. Değişkenlerin tümü için sabitli modelde temel hipotez reddedilmekte, alternatif hipotez kabul edilmektedir. Yani değişkenler, sabitli modelde seviyede birim kök içermektedir. Ancak birinci farkta tüm değişkenler durağan hale gelmekte, temel hipotez istatistiksel olarak \%1 anlamlılık düzeyinde kabul edilmektedir. Sabitli ve trendli modele ait sonuçlarda da GDP ve EXP değişkenlerinin düzey değerleri için IPS birim kök testinin temel hipotezi reddedilmektedir. Diğer bir ifade ile GDP ve EXP değişkenleri düzeyde birim köklüdür. IMP değişkeni ise düzeyde istatistiksel olarak \%5 anlamlılık düzeyinde durağandır. Ancak seviyede birim köklü olan GDP ve EXP değişkenleri birinci farkta \%1 anlamlılık düzeyinde durağan hale gelmektedir. Düzeyde $\% 5$ anlamlılık düzeyinde durağan olan IMP değişkeni ise birinci farkı alındıktan sonra \%1 anlamlılık düzeyinde durağan hale gelerek, durağanlık durumu istatistiksel olarak anlamlılık düzeyi duruma güçlü 
gelmektedir. Başka bir deyişle alternatif hipotez daha güçlü bir istatistiksel anlamlılık düzeyi ile reddedilmektedir. Dolayısıyla elde edilen sonuçlara göre değişkenlerin I(1) mertebesinde eşbütünleşik olduğu sonucuna varılmaktadır.

Tablo 1: IPS birim kök test sonuçları

\begin{tabular}{|c|c|c|c|c|}
\hline \multirow{2}{*}{$\begin{array}{l}\text { Model } \\
\text { Sabitli } \\
\end{array}$} & \multicolumn{2}{|c|}{ Düzey } & \multicolumn{2}{|c|}{ 1. Fark } \\
\hline & t-istatistik & p-değeri & t-istatistik & p-değeri \\
\hline $\operatorname{lnGDP}$ & 0.142 & 0.555 & -5.707 & $0.000 * * *$ \\
\hline EXP & -1.271 & 0.101 & -6.188 & $0.000 * * *$ \\
\hline IMP & -0.399 & 0.344 & -6.456 & $0.000 * * *$ \\
\hline \multicolumn{5}{|l|}{ Sabit ve Trend } \\
\hline $\operatorname{lnGDP}$ & -0.865 & 0.193 & -4.761 & $0.000 * * *$ \\
\hline EXP & -0.930 & 0.176 & -6.588 & $0.000 * * *$ \\
\hline IMP & -1.821 & $0.031 * *$ & -5.813 & $0.000 * * *$ \\
\hline
\end{tabular}

\section{Eşbütünleşme test sonuçları}

Birim kök testinden elde edilen bulgular ışı̆̆ında modele dâhil edilen tüm değişkenlerin I (1) mertebesinden eşbütünleşik olduğu görülmüştür. Eşbütünleşik olan değişkenlerin uzun dönem ilişkisinin olup olmadığına Pedroni (1999) Eşbütünleşme testi ile gerçekleştirilmiştir. Eşbütünleşme testine ait sonuçlar Tablo 2'de gösterilmiştir. Panel Eşbütünleşme test sonuçlarına bakıldığında, elde edilen 7 test istatistiklerinden 5 tanesi istatistiksel olarak anlamlıdır. Daha açık ifade edilecek olunursa modeldeki değişkenler arasında Panel-v istatistiğine göre \%1, Panel PP, Panel ADF ve Grup ADF istatistiklerine göre $\% 5$, Grup PP istatistiğine göre de $\% 10$ istatistiksel anlamlılık düzeyinde eşbütünleşme ilişkisi mevcuttur.

Tablo 2: Pedroni eşbütünleşme sonuçları

\begin{tabular}{lcc} 
Testler & t-istatistik & p-değeri \\
\hline Panel v-İstatistik & $8.014^{* * *}$ & 0.000 \\
Panel rho- İstatistik & 0.224 & 0.588 \\
Panel PP- İstatistik (parametrik olmayan) & $-1.924^{* *}$ & 0.027 \\
Panel ADF- İstatistik (parametrik) & $-2.054^{* *}$ & 0.020 \\
Group rho- İstatistik & 1.241 & 0.892 \\
Group PP- İstatistik (parametrik olmayan) & $-1.620^{*}$ & 0.052 \\
Group ADF-Statistic (parametrik) & $-1.916^{* *}$ & 0.027 \\
\hline
\end{tabular}

Not: $* * *, * *$ ve $*$ simgeleri sirasiyla $\mathrm{p}<0.01, \mathrm{p}<0.05$ ve $\mathrm{p}<0.10$ temsil etmektedir.

\section{Uzun dönem eşbütünleşme katsayı tahmin sonuçlart}

Eşbütünleşme ilişkisi elde edildikten sonra eşbütünleşme ilişkisine ait uzun dönem katsayı tahmin sonuçları FMOLS ile elde edilmiştir. FMOLS katsayı tahmin sonuçları Tablo 3 'te verilmiştir. Panele ait uzun dönem katsayı sonuçlarına göre sigortacılık hizmetleri ihracatını temsil eden EXP değişkenine ait katsayının \%1 anlamlılık düzeyinde istatistiksel olarak anlamlı ve pozitif olduğu Tablo 3 'te görülmektedir. Bu sonuca göre sigortacılık hizmetleri ihracatındaki \%1'lik artış ekonomik büyümeyi 0.029 arttırmaktadır. Sigortacılık hizmetleri ihracatının ekonomik büyüme üzerinde yatay kesitlere yani ülkelere ait sonuçlara bakıldığında sadece İngiltere için istatistiksel olarak anlamlı bir ilişki elde edilememiştir. Diğer ülkeler için istatistiksel olarak anlamlı sonuçlar elde edilmiştir.

Sigortacılık hizmetleri ithalatını temsil eden IMP değişkeninin ekonomik büyüme üzerindeki etkisi panele ait sonuçlara göre \%1 istatistiksel anlamlılık düzeyinde pozitif yönlüdür. Diğer bir ifade ile sağllk hizmetleri ithalatındaki \%1'lik artış ekonomik büyümeyi 0.006 kadar arttırmaktadır. Yatay kesitlere ait bulgulara bakıldığında İtalya hariç diğerlerinde ekonomik büyüme ve sigorta hizmetleri ithalat arasında istatistiksel olarak anlamlı ilişkiye rastlanmıştır. 
Tablo 3: FMOLS katsayı tahmin sonuçları

\begin{tabular}{lcccc}
\hline \multirow{2}{*}{ Ülkeler } & \multicolumn{2}{c}{ EXP } & \multicolumn{2}{c}{ IMP } \\
\cline { 2 - 5 } & Katsayı & $\begin{array}{c}\text { t-istatistik } \\
\text { [prob.] }\end{array}$ & Katsayı & $\begin{array}{c}\text { t-istatistik } \\
\text { [prob.] }\end{array}$ \\
\hline Kanada & $0.026^{* * *}$ & $9.585[0.000]$ & $0.023 * * *$ & $4.140[0.001]$ \\
Fransa & $0.030^{* * *}$ & $11.558[0.000]$ & $-0.025^{* * *}$ & $-6.749[0.000]$ \\
Almanya & $-0.014 *$ & $-1.936[0.067]$ & $0.045^{* * *}$ & $4.232[0.001]$ \\
İtalya & $-0.013^{* * *}$ & $-5.211[0.000]$ & -0.002 & $-0.792[0.437]$ \\
Japonya & $0.005^{* *}$ & $2.623[0.016]$ & $0.013 * * *$ & $4.871[0.000]$ \\
Rusya & $0.173^{* * *}$ & $26.903[0.000]$ & $-0.018^{* * *}$ & $-3.972[0.001]$ \\
İngiltere & -0.002 & $-1.442[0.167]$ & $0.027 * * *$ & $12.044[0.000]$ \\
Amerika Birleşik Devletleri & $0.030^{* * *}$ & $12.503[0.000]$ & $-0.013 * * *$ & $-5.964[0.000]$ \\
PANEL & $\mathbf{0 . 0 2 9} * * *$ & $\mathbf{2 1 . 8 7 0 [ 0 . 0 0 0 ]}$ & $\mathbf{0 . 0 0 6} * * *$ & $\mathbf{3 . 6 6 8}[\mathbf{0 . 0 0 1}]$ \\
\hline Not:
\end{tabular}

Not: $* * *, * *$ ve $*$ simgeleri sirasiyla $\mathrm{p}<0.01, \mathrm{p}<0.05$ ve $\mathrm{p}<0.10$ temsil etmektedir.

\section{Sonuç ve öneriler}

Hizmetler sektörünün gelişmesi nitelikli beşerî sermaye stoku, teknolojik gelişmelere katılım ve teknolojinin aktif kullanımı vb. farklı unsurların da ekonomi içinde aktif varlığına işaret etmektedir. Hizmetler sektörü de ulaşım, turizm, eğitim, sağlık, sigortacılık, finans gibi çeşitli alt sektörlerden oluşmaktadır. Dolayısıyla hizmetler sektörünün her alt sektörünün ekonomiler için önemi yadsınamaz. $\mathrm{Bu}$ bağlamda, sigortacılık hizmetlerinin ekonomik büyüme üzerindeki etkisinin ortaya konulmas1 amaçlanmıştır. Bu doğrultuda, G-8 ülkeleri için 1996-2019 dönemini kapsayan verilerle sigortacılık sektörünün ekonomik büyüme üzerindeki etkisi ortaya konulmuştur.

Çalışma panel veri teknikleri yardımıyla gerçekleştirilmiştir. Öncelikle serilere birim kök testi uygulanmıştır. Birim kök testi sonucunda tüm değişkenleri birinci farkta durağan olduğu görülmüştür. $\mathrm{Bu}$ sonucuna istinaden serileri panel eşbütünleşme testi uygulanmıştır. Eşbütünleşme testi sonuçlarından değişkenler arasında uzun dönem ilişki olduğu görülmüştür. Eşbütünleşme uzun dönem katsayı tahminleri ise FMOLS ile gerçekleştirilmiştir. Katsayı tahminleri, sigortacılık sektörünün ekonomik büyümeyi pozitif etkilediği göstermiştir.

Elde edilen sonuçlara göre sigortacılık hizmetlerinin ekonomik büyüme üzerinde pozitif etkisi olduğu görülmektedir. Sigortacılık hizmetlerinin gelişimi tasarruf sağlama, risklerin bertaraf edilmesi gibi farklı yönlerden ekonomiler için önem arz etmektedir. Elde edilen bulgular 1şı̆̆ında bir takım politika önerilerinde bulunacak olunursa, ülkede sigortacılık hizmetlerinin gelişmesi için gerekli yasal düzenlemeler yapılarak bu alana yönelik devlet teşviklerinin sağlanmalıdır. Sigortacılık hizmetleri çeşitlendirilerek en küçük ekonomik faaliyetlere varıncaya kadar sigortacılık hizmetleri yaygınlaştırılmalıdır. Sigorta primlerinin talep esnekliği de dikkate alınıp sigorta primleri makul düzeyde tutarak, bu hizmetlerden daha geniş kitlelerin faydalanması sağlanmalıdır.

\section{Kaynakça}

Adetunjiu, A. L., Nwude, E. C. \& Udeh, S. N. (2018). Interface of insurance and economic growth: Nigerian experience. International Journal of Economics and Financial Issues. 8 (4), 16-26.

Akın, F. (2018). MINT ekonomilerinin makroekonomik performansı ve sigortacılık sektörünün gelişimi üzerine bir değerlendirme. Maliye ve Finans Yazıları, 110, 71-94.

Akpınar, Ö. ve Yıldız, A. (2018). Küresel ekonomik krizin sigortacılık sektörüne etkisi ve kriz sonrası hayat diş1 sigortacilık sektörü performans analizi (2007-2016). Yüzüncü Yll Üniversitesi Sosyal Bilimler Enstitüsü Dergisi, 1 (39), 263-282.

Apergis, N. \& Poufinas, T. (2020). The role of insurance growth in economic growth: Fresh evidence from a panel of OECD countries. North American Journal of Economics and Finance, 53, 1-16.

Asunakutlu, T. (2001). Sigorta açısından güvenlik ve risk. Mevzuat Dergisi, Temmuz 2001, 4 (43).

Baltagi, B. H. (2005). Econometric analysis of panel data. Third Edition, John Wiley\&Sons Inc.

Demirci, S.. D. ve Zeren, F. (2017). Insurance premium and economic growth: Evidence from OECD countries. İsletme Bilimi Dergisi (JOBS), 5(1), 1-11. 
Ege, İ. ve Saraç, T.B. (2011). The relationshıp between insurance sector and economic growth: An econometric analysis. International Journal Economics Research, 2(2), 1-9.

Gümüş, E. (2020). OECD ülkelerinde insani gelişme ve finansal gelişme endeksleri ile sigortacilık prim üretimleri arasındaki ilişkinin incelenmesi. Troyacademy Uluslararası Sosyal Bilimler Dergisi, 5 (1), 149-172.

Hsiao, C. (2003), Analysis of panel data, Cambridge University Press, United Kingdom.

$\mathrm{Im}$, K.S., M.H. Pesaran \& Y. Shin (2003). Testing for unit roots in heterogeneous panels. Journal of Econometrics, 115, 53-74.

İslamoğlu, M., Hakim, A. ve Konak, A. (2020). Türkiye ve G-7 ülkelerinde bireysel emeklilik sistemi uygulamaları. Finans Ekonomik ve Sosyal Araştırmalar Dergisi, 5 (3), 557-570.

Karaman, D., ve Aydoğmuş, H. Y. (2020). Sigortacıllk sektörünün güncel sorunlarına yönelik ilişkisel pazarlama uygulamaları ekseninde çözüm önerileri. İşletme Araştırmaları Dergisi, 12(4), 39143929.

Kaya, N. ve Beşer, N. Ö. (2020). The effect of insurance premium on economic growth in European Union countries: Panel Data Analysis. Akademik Araştırmalar ve Çalışmalar Dergisi, 12 (23), 442-451.

Kumar, S., Sahu, N. C. \& Kumar, P. (2020). Insurance consumption and economic growth in the postliberalized 1ndia: An empirical analysis. Asian Economic and Financial Review, 10 (2), 218-228.

Lee, C., Lee, C. \& Chiu, Y. (2013). The link between life insurance activities and economic growth: Some new evidence. Journal of International Money and Finance, 32(1), 405-427

Lee, H., Yong, Z. \& Lim, Q. (2018). Insurance development and economic growth. Financial Statistical Journal, 1 (4), 1-17.

Matyas, L., ve Sevestre, P. (1996). The Econometrics of Panel Data: A Handbook of the Theory with Applications. Second Revised Edition, Kluwer Academic Publishers, Netherlands.

Pedroni, P. (1999). Critical values for cointegration tests in heterogeneous panels with multiple regressors. Oxford Bulletin of Economics and Statistics, 61, ss. 653-670.

Pedroni, P. (2000). Fully-modified OLS for heterogeneous cointegrated panels. Advances in Econometrics, 15, 93-130.

Pradhan, R. P., Arvin, M.B., Nair, M., \& Hall, J.H., ve Gupta, A. (2017). Is there a link between economic growth and insurance and banking sector activities in the G-20 countries?. Review of Financial Economics, 33 (1), 12-28.

Pradhan, R. P., Arvin, M. B. \& Norman, N. R. (2015). Insurance development and the finance-growth nexus: evidence from 34 OECD countries. Journal of Multinational Financial Management, 31, $1-22$.

Pradhan, R. P., Arvin, M. B., Norman, N. R., Nair, M. \& Hall, J. H. (2016). Insurance penetration and economic growth nexus: Cross-country evidence from ASEAN. Research in International Business and Finance, 36, 447-458.

Sezal, L. (2017). Türkiye sigortacılık sektörünün değerlendirilmesi ve faizsiz sigortacılık sisteminin uygulanabilirliği. Uluslararası Sosyal Araştırmalar Dergisi, 10 (52), 1156-1167.
World Bank, World Development Indicators, https://databank.worldbank.org/reports.aspx ? source=2\&series=NY.GDP.MKTP.CD\&country=\# (04.03.2021)

Yenisu, E. (2019). Sigortacılık sektörü ve ekonomik büyüme ilişkisi: Türkiye örneği. Finans Ekonomi ve Sosyal Araştırmalar Dergisi, 4 (2), 206-217.

\section{Etik kurul onayı}

Yukarıda bilgileri yer almakta olan çalışmamın araştırma makalesi olması ve ikincil verilerin ekonometri paket programları ile analiz edilmesi sebebiyle etik kurul izni gerektirmeyen çalışmalar arasında yer aldığını beyan ederiz.

\section{Araştırmacıların katkı oranı beyanı}

Yazarlar çalışmaya eşit oranda katkı sağlamıştır

Çıkar çatışması beyanı

Herhangi bir çıkar çatışması bulunmamaktadır. 